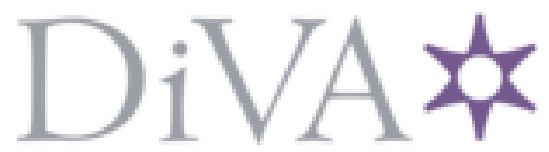

http://www.diva-portal.org

This is the published version of a paper published in Dalton Transactions.

Citation for the original published paper (version of record):

Ahlsten, N., Bartoszewicz, A., Martín-Matute, B. (2012)

Allylic alcohols as synthetic enolate equivalents: Isomerisation and tandem reactions catalysed by transition metal complexes.

Dalton Transactions, 41(6): 1660-1670

https://doi.org/10.1039/c1dt11678a

Access to the published version may require subscription.

N.B. When citing this work, cite the original published paper.

Reprinted with permission of Dalton Transactions, 2012, 41 (6), 1660-1670. Copyright 2012 The Royal Society of Chemistry.

Permanent link to this version:

http://urn.kb.se/resolve?urn=urn:nbn:se:su:diva-76742 


\title{
Transactions
}

Cite this: Dalton Trans., 2012, 41, 1660

wWW.rsc.org/dalton

PERSPECTIVE

\section{Allylic alcohols as synthetic enolate equivalents: Isomerisation and tandem reactions catalysed by transition metal complexes}

\author{
Nanna Ahlsten, ${ }^{a, b}$ Agnieszka Bartoszewicz ${ }^{a, b}$ and Belén Martín-Matute ${ }^{* a, b}$ \\ Received 5th September 2011, Accepted 4th November 2011 \\ DOI: 10.1039/c1dt11678a
}

\begin{abstract}
Allylic alcohols can be isomerised into carbonyl compounds by transition metal complexes. In the last few years, catalyst design and development have resulted in highly efficient isomerisations under mild reaction conditions, including enantioselective versions. In addition, the isomerisation of allylic alcohols has been combined with $\mathrm{C}-\mathrm{C}$ bond forming reactions when electrophiles such as aldehydes or imines were present in the reaction mixture. Also, $\mathrm{C}-\mathrm{F}$ bonds can be formed when electrophilic fluorinating reagents are used. Thus, allylic alcohols can be treated as latent enol(ate)s. In this article, we highlight the latest developments concerning the isomerisation of allylic alcohols into carbonyl compounds, focusing in particular on tandem isomerisation/C-C or C-heteroatom bond formation processes. Significant attention is given to the mechanistic aspects of the reactions.
\end{abstract}

\section{Introduction}

Two excellent general reviews by the groups of Bouwman and coworkers $^{1}$ and Grée and co-workers ${ }^{2}$ on the isomerisation of allylic alcohols catalysed by several transition metal complexes cover the results obtained until 2003, and more recently, in 2008, Gimeno and co-workers published a review on ruthenium-catalysed isomerisation of allylic and propargylic alcohols in aqueous and organic media. ${ }^{3}$ Very recently, a review by Mazet and Mantilli covers the latest developments on asymmetric isomerisation of primary allylic alcohols. ${ }^{4}$ In this article, we aim to give an overview of this isomerisation, and in particular of the progress achieved recently, with an emphasis on synthetic applications (e.g., tandem reactions), mechanistic investigations, and our own contribution to this field.

\section{Isomerisation of allylic alcohols: Scope and mechanism}

Isomerisation of allylic alcohols into carbonyl compounds can be catalysed by several transition metal complexes, in particular from the groups 8, 9 and 10 (Scheme 1b). ${ }^{1,2,3}$ Such a one-pot catalytic redox transformation is an atom-economical ${ }^{5}$ alternative to a two-step sequential process involving alcohol oxidation and reduction of the alkene functionality (or vice versa) (Scheme 1a). In this way, the use of (super)stoichiometric amounts of costly and toxic reagents is avoided. Another advantage of the transitionmetal-catalysed redox isomerisation is that high chemoselectivity

${ }^{a}$ Address, Department of Organic Chemistry, Arrhenius Laboratory, Stockholm University,SE-106 91, Stockholm,Sweden.E-mail: belen@organ. su.se; Fax: +468154908

${ }^{b}$ Berzelii Centre EXSELENT on Porous Materials, Stockholm University, SE-106 91, Stockholm, Sweden (a)

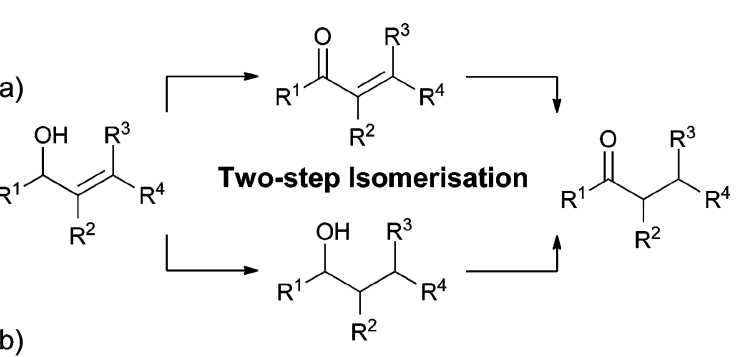

(b)<smiles>[R]C(O)=C([R])[Hg]</smiles>

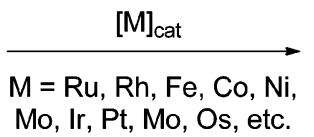<smiles>[R]C(=O)C([R])[1H]</smiles>

Redox Isomerisation

Scheme 1 Conversion of allylic alcohols into carbonyl compounds by (a) stoichiometric sequential oxidation/reduction reactions, or (b) transition metal-catalysed redox isomerisation.

is usually obtained (i.e., allylic alcohols can be isomerised in the presence of additional double bonds, alcohol or ketone moieties).

The first isomerisation procedures to be reported required harsh reaction conditions (long reaction times and high temperatures), and by-products, such as saturated alcohols or enones were formed. Fortunately, excellent results in terms of selectivity and yields can be obtained nowadays. This improvement is due to the synthesis and rational design of new transition metal complexes, variation of the reaction conditions, and mechanistic investigations at both experimental and computational levels. ${ }^{1,2,3,6,7}$

Back in 2005, we reported that the cyclopentadienyl ruthenium complex 1 (Fig. 1) isomerises allylic alcohols in excellent yields when a catalytic amount of ${ }^{t} \mathrm{BuOK}$ is added to the reaction mixture. ${ }^{6 c}$ The use of this basic reagent, which promotes catalyst activation by replacement of the chloride ligand by $t$-butoxide, 
was essential for the success of the reaction. Thus, the isomerisation of a variety of allylic alcohols took place at room temperature, and quantitative yields could be obtained in short reaction times. Simultaneously, Ikariya reported another highly reactive cyclopentadienyl ruthenium complex (2a, Fig. 1) bearing a bidentate $P, N$-ligand that functioned at room temperature in short reaction times. ${ }^{6 \mathrm{~d}}$ This catalyst was also activated by ${ }^{t} \mathrm{BuOK}$. In this case, the role of the base was attributed to the formation of a catalytically active 16-electron intermediate. When a chiral $P, N$-ligand was used, the asymmetric isomerisation of racemic sec-allylic alcohol $\mathbf{3}$ was achieved and applied as the key step in the synthesis of muscone (Scheme 2). It has been shown that many other metal halide complexes in combination with ${ }^{t} \mathrm{BuOK}$ are excellent catalytic systems for the isomerisation of allylic alcohols. ${ }^{3,6 h, 8}$

Despite the significant progress achieved in the past decade, there are still some challenges in the isomerisation of allylic alcohols. For example, the isomerisation of highly substituted substrates, such as allylic alcohols bearing tetrasubstituted double bonds, is rare. ${ }^{6 \mathrm{~g}}$ Another feature is that complexes showing excellent catalytic activity in the isomerisation of sec-allylic alcohols, usually do not perform well in the isomerisation of primary allylic alcohols, and vice versa. The former case has been explained in

Agnieszka Bartoszewicz (left) was born in Skarzysko-Kamienna (Poland) and received her M.S. degree from Warsaw University in 2006 under the supervision of Prof. Tomasz Bauer. In 2007, she did a research project at Stockholm University in the group of Prof. Jacek Stawinski. Since 2008, she has been a Ph.D student with Prof. Belén Martín-Matute at Stockholm University. Belén MartínMatute (centre) was born in Madrid and obtained her Ph.D at the Universidad Autónoma de Madrid (UAM 2002) with Prof. A. M. Echavarren. After a postdoctoral stay at Stockholm University with Prof. J.-E. Bäckvall, she joined the UAM as an Assistant Professor (2005-2007). She returned to Stockholm in 2007, where in 2011 she became Associate Professor. She received the Sigma-Aldrich Young Chemist Award from the Spanish Royal Society of Chemistry in 2007. Nanna Ahlsten (right) was born in Gotland (Sweden) and obtained her M.Sc. from Lund University in 2008. In the same year, she joined the research group of Prof. Belén Martin-Matute at the Department of Organic Chemistry at Stockholm University, where she is currently a Ph.D student.

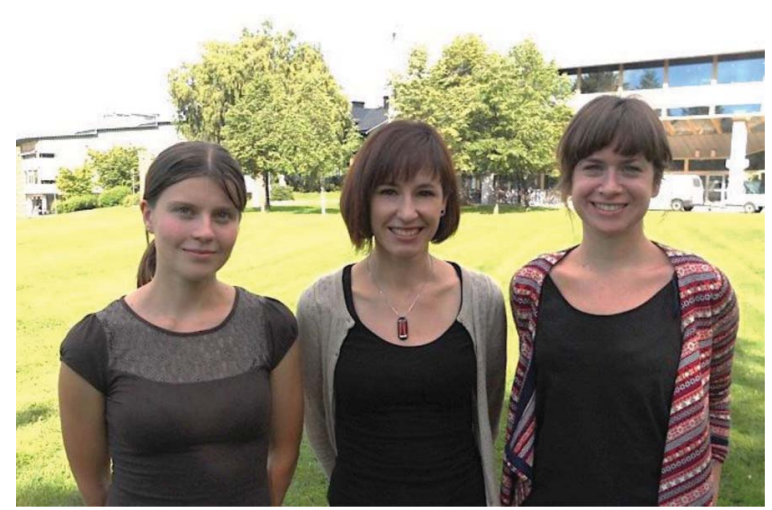

Agnieszka Bartoszewicz, Belén Martín-Matute, Nanna Ahlsten
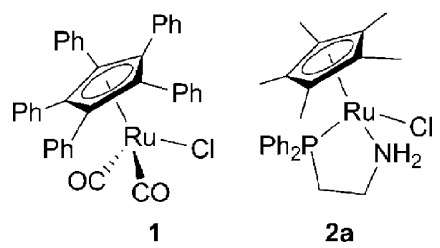

Fig. $1 \mathrm{Ru}(\mathrm{II})$-complexes for isomerisation of allylic alcohols at ambient temperature.

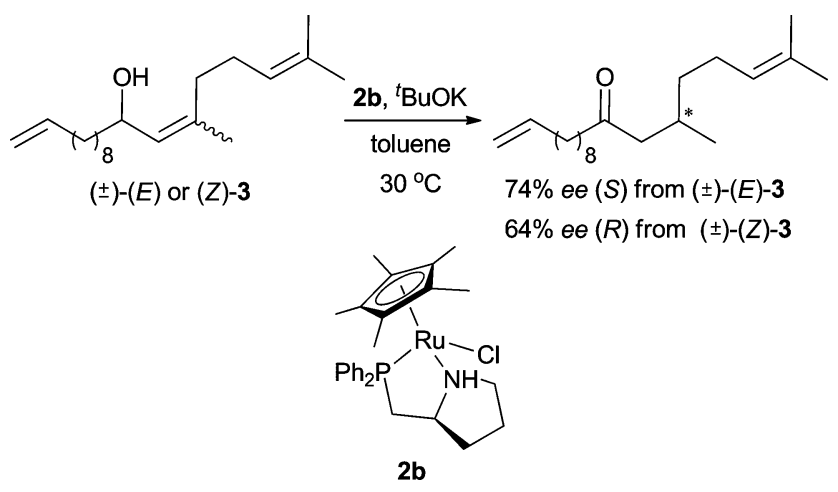

Scheme 2 Ikariya's asymmetric isomerisation of a sec-allylic alcohol.

some instances by the high reactivity of the aldehyde products under the reaction conditions, which results in the formation of aldols from self-condensation reactions. ${ }^{9,10}$ Aldehydes can also be decarbonylated, yielding transition metal carbonyl complexes, which may not show the desired reactivity. ${ }^{11}$ Despite these difficulties, highly efficient systems in the isomerisation of primary allylic alcohols have been reported very recently. For example, Esteruelas, García-Yebra and co-workers prepared a cationic osmium(II) complex (4) able to isomerise certain primary allylic alcohols into aldehydes in excellent yields (Scheme 3). ${ }^{10,12}$ Mazet and co-workers used iridium dihydrides generated in situ from an analogue of Crabtree's catalyst and hydrogen in the isomerisation of primary allylic alcohols. ${ }^{6 g}$ The catalytic system was later further modified by introduction of a chiral ligand and used in asymmetric isomerisations (vide infra). ${ }^{7}$

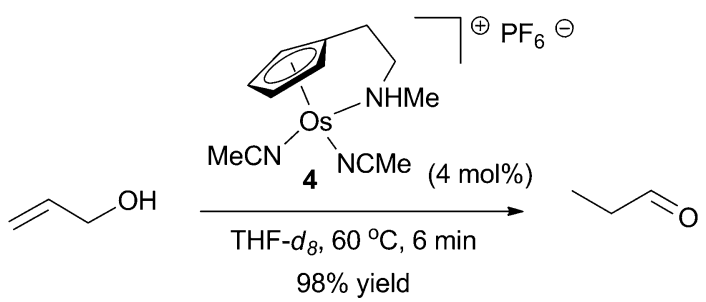

Scheme 3 Isomerisation of primary allylic alcohols catalysed by an Os(II) complex.

In contrast with the few reports on asymmetric isomerisation of sec-allylic alcohols, ${ }^{60,13}$ numerous examples of enantioselective isomerisation of primary allylic alcohols exist. ${ }^{4}$ After a first example by Tani in 1985, who obtained a moderate yield (47\%) and enantioselectivity $(53 \% e e)$ in the isomerisation of $(E)$-3-phenylbut-2-en-1-ol with [Rh(BINAP)(COD) $] \mathrm{BF}_{4},{ }^{14} \mathrm{Fu}$ and co-workers reported the use of a planar-chiral phosphaferrocene ligand and obtained high levels of enantioselectivity (Scheme 4). ${ }^{15}$ 


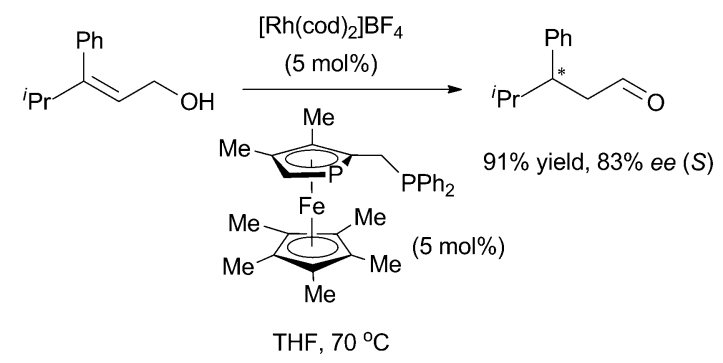

Scheme $4 \mathrm{Rh}$ catalysed asymmetric isomerisation of primary allylic alcohols using a planar-chiral phosphaferrocene ligand.

In 2009, Mazet and co-workers reported the synthesis of their second generation of highly efficient iridium catalysts, ${ }^{6 \mathrm{~g}}$ where the use of chiral (dialkyl)phosphinoalkyloxazoline ligands afforded excellent results in the asymmetric isomerisation of primary allylic alcohols (Scheme 5). ${ }^{7}$ A recent review by the same author highlights all the achievements obtained to date in the asymmetric isomerisation of primary allylic alcohols. ${ }^{4}$ Very recently, Andersson and co-workers have reported a similar iridium-based catalytic system using a variety of $P, N$-ligands developed in their research group in the enantioselective isomerisation of primary allylic alcohols. ${ }^{16}$

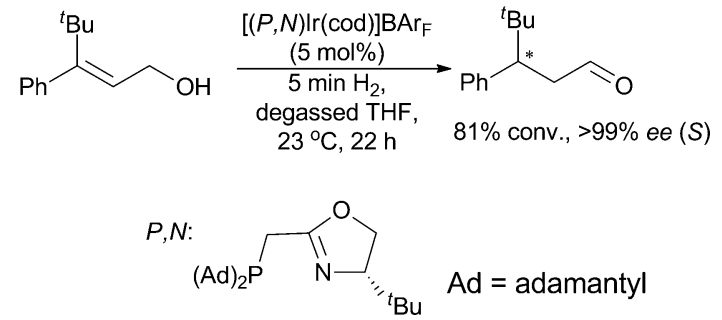

Scheme 5 Asymmetric isomerisation of primary allylic alcohols by a chiral iridium complex.

Although most of the catalytic systems employed in isomerisation of allylic alcohols are used in organic media, there are some examples where biphasic organic/aqueous or only aqueous media is used. The complexes are usually modified with water-soluble ligands (e.g., sulfonated aromatic phosphines), ${ }^{17}$ or their cationic character makes them soluble in the aqueous solvent. Most of these systems use complexes of $\mathrm{Ru}^{18,19,20,21,22 a, 23,24} \mathrm{Rh}^{11,226,25,26,27,28}$ and Ni. ${ }^{29}$ Among these examples, only few transition metal complexes are able to isomerise allylic alcohols in water at mild reaction conditions using low catalyst loadings. ${ }^{18,19,22 a, 28,30} \mathrm{An}$ exceptionally active family of $\mathrm{Ru}(\mathrm{IV})-\mathrm{Cl}$ complexes (i.e., $\mathbf{5} \mathbf{a}-\mathbf{b}$ in Fig. 2) prepared by Cadierno, Gimeno and co-workers showed TOF's of up to $50000 \mathrm{~h}^{-1}$ and TON's of $10^{6}$ for the isomerisation of 3-buten-2-ol into butan-2-one at $75^{\circ} \mathrm{C}$ in water. ${ }^{18}$ Higher catalyst loadings were needed for more sterically hindered allylic alcohols. Recently, the same authors reported a related Ru(IV) acetate
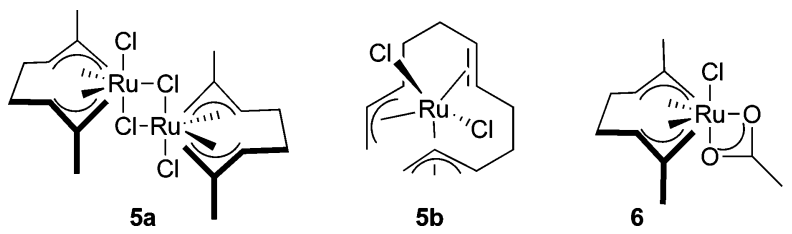

Fig. $2 \mathrm{Ru}(\mathrm{IV})$ catalysts for isomerisation of allylic alcohols in water. complex (6), that isomerises 1-octen-2-ol at ambient temperature in water or ionic liquids efficiently. ${ }^{20}$

As mentioned above, we have used $\mathrm{Ru}$ and $\mathrm{Rh}$ chlorides in combination with ${ }^{t} \mathrm{BuOK}$ to displace the halide and promote an isomerisation mechanism via transition metal alkoxides in organic solvents. ${ }^{6 c}$ We rationalised that metal-hydroxo or metalaqua complexes could easily form if water was used as the solvent. We found that the cationic complex $\left[\mathrm{Rh}(\mathrm{COD})\left(\mathrm{CH}_{3} \mathrm{CN}\right)_{2}\right] \mathrm{BF}_{4}$ in combination with 1,3,5-triaza-7-phosphaadamantane (PTA) as the ligand is a very efficient catalyst for the isomerisation of secondary and some primary allylic alcohols at room temperature in water. The active complex, which can be used with catalyst loadings as low as $0.5 \mathrm{~mol} \%$, is formed in situ from commercially available reagents. For example, isomerisation of $\alpha$-vinylbenzyl alcohol occurs within $5 \mathrm{~min}$ at ambient temperature using $2 \mathrm{~mol} \%$ of $\mathrm{Rh}$ (Scheme 6).

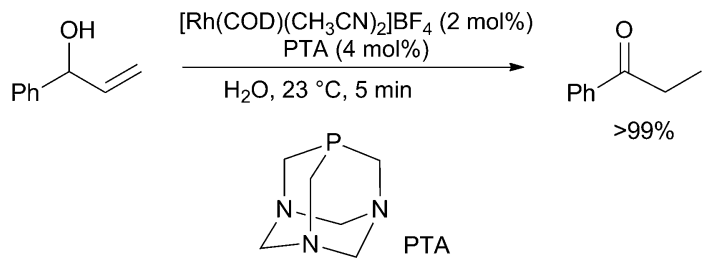

Scheme 6 Rh catalysed isomerisation in water at ambient temperature.

Transition metal complexes immobilised on solid supports have been used in the isomerisation of allylic alcohols as well. For example, Mizuno and co-workers reported that $\mathrm{Ru}(\mathrm{OH})_{x}$ supported on alumina is an excellent catalyst for isomerisation and for tandem isomerisation/transfer hydrogenation using ${ }^{i} \mathrm{PrOH}$ as the hydrogen donor (Scheme 7). ${ }^{31}$ Our own research group has immobilised a cationic rhodium complex onto a mesoporous silica material (Al-SBA-15). The heterogeneous catalyst, which can be recycled, isomerises sec-allylic alcohols and some primary allylic alcohols with high efficiency. ${ }^{32}$

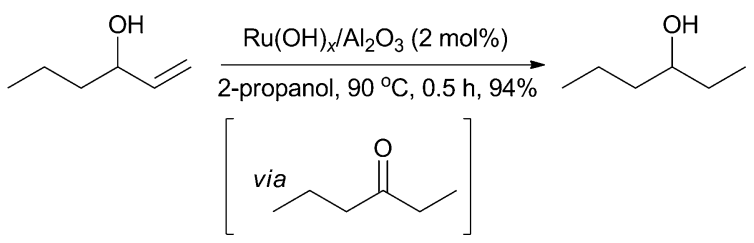

Scheme 7 Isomerisation catalysed by a heterogeneous catalyst.

\section{Allylic alcohol isomerisation mechanisms}

Different mechanistic proposals have been suggested for the transition-metal-catalysed isomerisation. In all of them, transition metal hydrides play a key role. ${ }^{33}$ Metal hydrides can be introduced directly as pre-catalysts or formed in situ via oxidation of the allylic alcohols. Three general mechanisms (types $A-C$ ), which involve transition metal hydride species, have been considered although only one of them (mechanism $A$, Scheme 8 ) assigns a specific role to the oxygen moiety of the allylic alcohol. In this mechanism, first proposed by Trost, ${ }^{11 \mathrm{~d}}$ enones formed by oxidation of the alcohol functionality are key intermediates. ${ }^{6 c}$ The oxidation of the substrate involves concomitant formation of a metal hydride. 
(a)<smiles>[M]OC(C)=CC(C)=CC(C)=O</smiles><smiles>C=CC(C)O[Na]</smiles>

(b)<smiles>Cc1ccccc1O</smiles><smiles>CCCC(=O)CC/C=C(/C)O[Na]</smiles>

Scheme 8 Mechanism via enone intermediates (type- $A$ mechanism).

In a subsequent step, the hydride is delivered to the enone $\beta$ carbon either via a migratory insertion (path a) or via a 1,4hydride addition (path $\mathrm{b}$ ). In the first scenario, an isomerisation of the $C$-bound enolate to the $O$-bound enolate may be required. Bergman and co-workers have prepared and characterised a variety of transition metal enolates, ${ }^{34}$ and they have studied the transformation of $\eta^{1}-C$-bound into $\eta^{1}$ - $O$-bound enolates (and vice versa), which occurs via $\eta^{3}$-oxaallyl intermediates (Scheme 9). ${ }^{34 \mathrm{~b}}$ Path $b$ in Scheme 8 has been proposed based on the fact that some catalysts only isomerise allylic alcohols that, upon oxidation, yield enones able to adopt an s-cis conformation. ${ }^{35}$ Throughout type- $A$ mechanism, the olefin moiety may also coordinate to the metal centre (not shown in the Scheme 8). It has been concluded from crossover experiments that the hydride transfer can occur in an intramolecular fashion when the reaction is run under mild reaction conditions. However, when using higher temperatures or with more sterically crowded substrates, the enone intermediate may decoordinate, resulting in an intermolecular hydrogen transfer. ${ }^{6 c}$

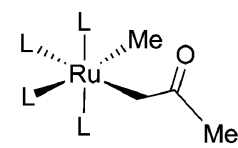

$\eta^{1}$-C-bound enolate<smiles>C[13CH]=[14C](C)CC(C)=O</smiles><smiles>C=C</smiles>

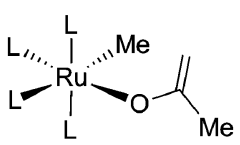

$\eta^{1}$-O-bound enolate<smiles>CC(C)(C)C</smiles>
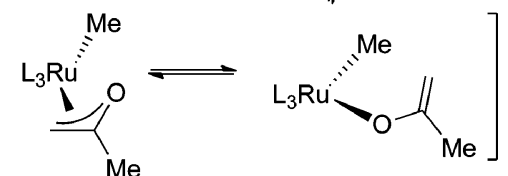

$\eta^{3}$-oxaallyl intermediate

Scheme 9 Isomerisation of enolates via haptomeric equilibrium.

The use of additives affects the isomerisation efficiency and mechanism. Spectacular rate accelerations by addition of base are well documented in $\mathrm{Ru}$ catalysed reactions involving hydrogen transfer. ${ }^{6 c, 36,37}$ Under basic conditions, metal allylic alkoxides are likely catalytic intermediates. These species may be produced by alkoxide ligand exchange processes (Scheme 10a), or by direct deprotonation of metal-coordinated allylic alcohols (Scheme 10b). The former case has been proposed to occur when additives such as alkoxides (i.e., ${ }^{t} \mathrm{BuOK}$ ) are used to promote halogen displacement from the, otherwise inactive, metal halide pre-catalysts. The latter

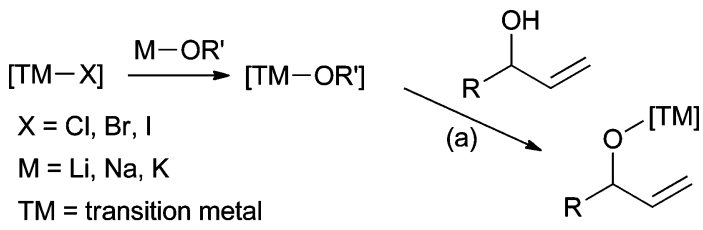

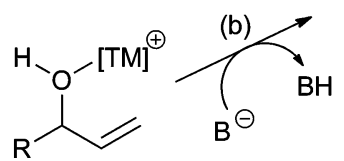

Scheme 10 Base-mediated formation of transition metal alkoxides.

is believed to take place in some carbonate assisted isomerisation of allylic alcohols catalysed by $\mathrm{Ru}(\mathrm{IV})$ complexes. ${ }^{18}$

A theoretical analysis of the mechanism operating with Ru(IV) complexes such as 5a (vide supra, Fig. 2) by Gimeno, Sordo and coworkers ${ }^{18,33}$ led to the proposal of a type- $A$ mechanism, involving coordination of both the olefin and the alcohol functionality. Mechanistically related is the isomerisation of allylic alcohols catalysed by bifunctional complexes, such as the $\mathrm{Cp} * \mathrm{Ru}(P, \mathrm{~N})(\mathbf{2 a})$ family reported by Ikariya, ${ }^{6 \mathrm{~d}}$ which also involves the formation of enone intermediates (Scheme 11). Unlike the mechanism described above, the oxygen moiety does not coordinate to the metal center. Instead, a 16-electron ruthenium complex dehydrogenates the allylic alcohol in a concerted process in which the alcohol proton $(\mathrm{CH}-\mathrm{OH})$ and the $\alpha$-hydrogen $(\mathrm{CH}-\mathrm{OH})$ are transferred regiospecifically to the $\mathrm{NH}$ group and to the metal, respectively.

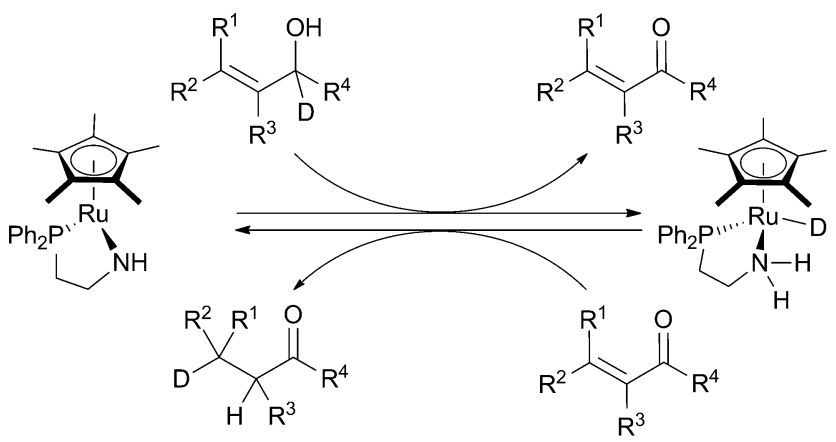

Scheme 11 Isomerisation of allylic alcohols catalysed by bifunctional catalysts.

A second mechanistic alternative is depicted in Scheme 12 (type$B$ mechanism), where transition metal hydrides react directly with allylic alcohols. The hydride ligand may be present in the precatalyst, or be produced in situ upon oxidation of a sacrificial amount of allylic alcohol. Insertion of the olefin of the allylic alcohol into the metal-hydride bond, followed by $\alpha-\mathrm{C}-\mathrm{H}$ bond cleavage ( $\beta$-hydride elimination) leads to an enol and regenerates the metal-hydride complex. It is important to note that type- $B$ mechanism involves an intermolecular hydrogen transfer. ${ }^{2,7}$ Thus, as demonstrated by McGrath and Grubbs, ${ }^{19}$ it can be identified

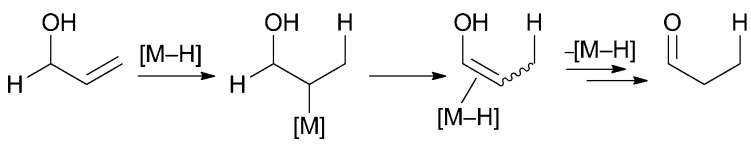

Scheme 12 Isomerisation of allylic alcohols catalysed by metal monohydride complexes (type- $B$ mechanism). 
by performing crossover experiments with differently isotopically labelled allylic alcohols (Scheme 13). (a)<smiles>[14CH2]=CCO</smiles>

(b)<smiles>[14CH2]=CCO</smiles><smiles>[R9]C(O)C=C</smiles><smiles></smiles>

$$
\underset{\text { tos }=p \text {-toluenesulfonate }}{\stackrel{\mathrm{Ru}\left(\mathrm{H}_{2} \mathrm{O}\right)_{6}(\mathrm{tos})_{2}}{\mathrm{D}_{2} \mathrm{O}}}
$$

Scheme 13 (a) Crossover experiment with differently isotopically labelled substrates; (b) isomerisation in $\mathrm{D}_{2} \mathrm{O}$.

Mazet and co-workers have proposed a type- $B$ mechanism in the asymmetric isomerisation of primary allylic alcohols catalysed by chiral iridium dihydrides (vide supra, Scheme 5). Although two hydride ligands are present in the active catalytic species (Fig. 3), in the productive catalytic cycle only one of them is positioned favorably to undergo migratory insertion. ${ }^{6 g, 7}$

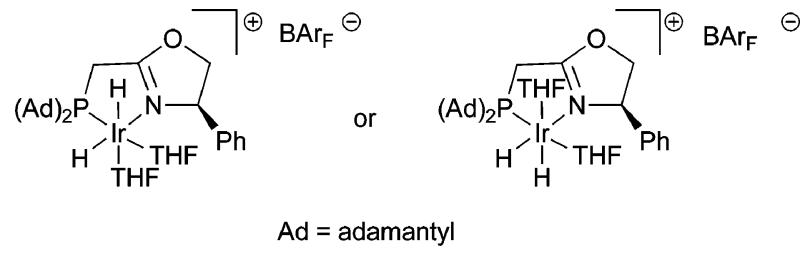

Fig. 3 cis-Dihydride intermediates in asymmetric isomerisation of primary allylic alcohols.

In the last mechanism (type- $C$, Scheme 14), an enol is generated via $\pi$-allyl metal hydride intermediates, formed by oxidative addition of the allylic $\mathrm{C}-\mathrm{H}$ bond. Thus, this mechanism involves changes in the oxidation state of the transition metal. In contrast with type- $B$ mechanism, the hydrogen transfer occurs intramolecularly.

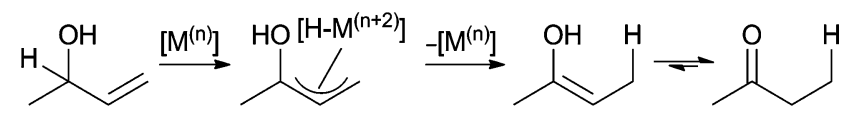

Scheme 14 Isomerisation of allylic alcohols via metal $\pi$-allyl intermediates (type- $C$ mechanism).

Type- $C$ mechanism was proposed to be operative in the $\mathrm{Fe}(\mathrm{CO})_{5}$-catalysed allylic alcohol isomerisation reported by Rosenberg and Cowherd as early as in the $1960 \mathrm{~s},{ }^{38}$ and more recently supported by a computational study by Branchadell and co-workers for the same catalytic system. ${ }^{39}$ This mechanism was also suggested for the Os catalysed isomerisation of allylic alcohols reported by Esteruelas and García-Yebra (Scheme 3, vide supra).${ }^{10}$ They isolated the hydroxoallyl complex 7 upon reaction of 4 with 2-methyl-2-propen-1-ol (Scheme 15). The structure of 7 was confirmed by X-ray diffraction analysis, which indicated the presence of a stabilising intramolecular hydrogen bond between the amine ligand and hydroxyl functionality. Based on the stability of complex 7 and isotope effect studies, the authors proposed that the migration of the hydride ligand from osmium

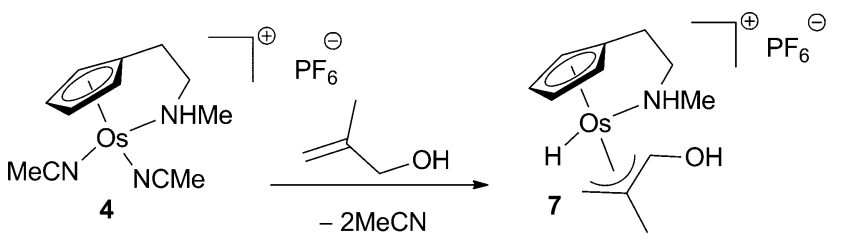

Scheme $15 \pi$-Allyl osmium hydride complex.

to the hydroxyallyl group is the rate-determining step of the isomerisation.

Although proceeding via different intermediates and metal oxidation states, type- $A$ and type- $C$ mechanisms are difficult to distinguish experimentally from one another since both may involve an intramolecular 1,3-hydrogen shift.

An alternative mechanism to those shown above for the transition-metal-catalysed conversion of allylic alcohols into ketones would be a sigmatropic suprafacial 1,3-hydrogen shift, as first proposed by Rosenberg. ${ }^{38}$ No experimental evidence supporting this mechanism has been obtained so far. ${ }^{33}$

\section{Allylic alcohols as latent enolates}

Enolates are key intermediates in synthetic organic chemistry for constructing new carbon-carbon and carbon-heteroatom bonds. Thus, the development of new strategies to generate enolates in a regioselective manner is extremely important. ${ }^{40}$ Although regioselective deprotonation of unsymmetrical ketones may be achieved by choosing appropriate reaction conditions under thermodynamic or kinetic control, a mixture of regioisomers is usually produced when both substituents adjacent to the carbonyl moiety have similar steric and electronic properties. Furthermore, in some cases formation of one of the possible regioisomeric enols may be favoured both kinetically and thermodynamically, and thus selective formation of the non-favored regioisomer is impossible by this approach. Alternatively, regioselective synthesis of enolates can be achieved using different synthetic enolate equivalents. For example, stoichiometric reduction of enones using lithium in liquid ammonia produces specific lithium enolates (Scheme 16a). ${ }^{41}$ This method suffers, however, from a low functional group tolerance. A much more attractive method is the in situ formation of enolates from enones mediated by transition metal complexes using stoichiometric reductants such as silanes or dihydrogen. ${ }^{42,43}$ Since enolates are produced under very mild reaction conditions, and the catalytic systems show high functional group tolerance, the reduction can be performed in the presence of electrophiles such as aldehydes and imines, resulting in the formation of new

(a)<smiles>[R]C=CC(=O)C[R1]</smiles>

(b)<smiles>[R]C=CC(=O)C[R]</smiles>

(c)<smiles>[R]C=CC(O)(O)C[R]</smiles>

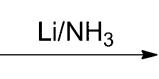<smiles>[R][CH]/C=C(/C[R])O[SiH3]</smiles>

Scheme 16 Generation of enolates from enones and allylic alcohols. 
C-C bonds (Scheme 16b) ${ }^{43,44}$ Allylic alcohols have also been used as enolate precursors in tandem reactions with formation of a new $\mathrm{C}-\mathrm{C}$ bond (Scheme 16c). ${ }^{1,2,3,40}$ In contrast to the reduction of enones, a stoichiometric reductant is not needed. As seen in the previous section, in the absence of electrophiles, the enols formed via protonation of the enolates tautomerise into the corresponding carbonyl compounds. However, if electrophiles such as aldehydes or imines are present in the reaction media, aldol and Mannichtype products are formed, respectively.1,2,3 An advantage of these last two approaches for synthesising enol(ate)s is that transition metal enolates have a softer character than those of the main group metals. Hence functional group tolerance is generally high and the electrophiles can be present in the reaction flask from the outset. On the other hand, transition metal enolates are less reactive than those of main group metals. As a consequence, only activated or very reactive electrophiles can be used. In all three methods presented in Scheme 16 the enolate is formed at the carbon originating from the olefin in the starting enone or allylic alcohol, resulting in the formation of enolates as single constitutional isomers.

In the next sections of this review, only tandem or domino reactions are described..$^{45}$ In these processes, only one set of reagents is added for an entire sequence of reactions to occur. The intermediate or product formed in the first transformation reveals functionality that allows a second transformation to occur (and so on). Thus, all reagents must show the desired reactivity and compatibility under the reaction conditions. Examples in which transition metal enolates, formed from allylic alcohols, react with electrophiles such as aldehydes and imines (tandem isomerisation/ $\mathrm{C}-\mathrm{C}$ bond formation) or electrophilic fluorinating reagents (tandem isomerisation/C-F bond formation) are given. Also, a few examples where allylic alcohols are isomerised to the corresponding carbonyl compounds and that are further funtionalised in a reaction catalysed by the same transition metal complex, will be presented. Sequential reactions, where reagents are added and/or reaction conditions are changed to promote a subsequent transformation are outside the scope of this review.

\subsection{Tandem isomerisation/C-C bond formation from allylic alcohols}

The tandem isomerisation/C-C bond formation from allylic alcohols is a highly atom economical process, in particular in those cases where the use of stoichiometric amounts of base can be avoided. Still, a few limitations have to be overcome. For example, protonation of the enolate intermediates and/or fast tautomerisation of the enol products result in the formation of saturated carbonyl compounds without concomitant formation of a new $\mathrm{C}-\mathrm{C}$ bond. For this reason, an excess of the allylic alcohols needs to be used in some instances. Bergens and Bosnich, reported in $1991 \mathrm{a} \mathrm{Rh}$ catalysed transformation of allylic alcohols into enols, and observed that the enols formed in the reaction were remarkably stable in acetone. ${ }^{46}$ In a subsequent step, a variety of electrophiles (i.e., tetracyanoethylene, $N, N$ dimethyliminium iodide or toluenesulfonyl isocyanate) were added to the reaction mixture resulting in the synthesis of $\alpha$-substituted carbonyl compounds (Scheme 17). Motherwell and Sandham used $\mathrm{Rh}$ complexes to catalyse the formation of Li-enolates from allylic alkoxides formed upon treatment of the allylic

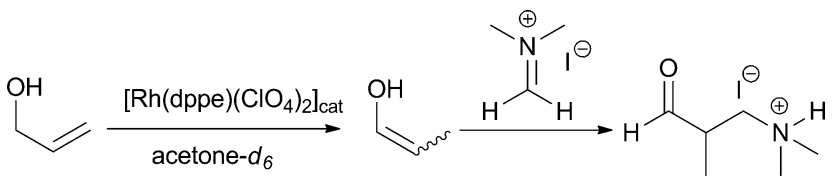

Scheme 17 Isomerisation of allylic alcohols into enols, and subsequent trapping with $N, N$-dimethyliminium iodide.

alcohol with stoichiometric amounts of ${ }^{n} \mathrm{BuLi} \cdot{ }^{47}$ The enolates were reacted in a consecutive step with aldehydes and allyl halides. These examples are sequential transformations. Nevertheless, they are the first examples showing the enormous potential of allylic alcohols in synthetic transformations leading to new $\mathrm{C}-\mathrm{C}$ bonds.

Since then, several catalytic systems that do not require the use of stoichiometric amount of base and that are compatible with electrophilic species present in the reaction media have been reported (vide infra). In these tandem transformations the most common electrophiles are aldehydes and imines (Scheme 18).

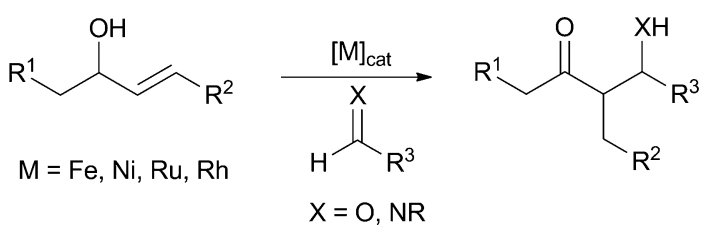

Scheme 18 Tandem isomerisation/C-C bond formation.

The first examples were reported by Grée and co-workers who used iron carbonyl complexes as catalysts to couple aliphatic allylic alcohols with a variety of aldehydes. ${ }^{48}$ Aldol products were formed in high yields. The process also afforded small amounts of undesired isomeric aldol products together with ketones from isomerisation of the allylic alcohol (Scheme 19). ${ }^{48}$ The same group reported in 2001 the use of ruthenium and rhodium complexes and moderate to good yields were obtained using $[\mathrm{Ru}-\mathrm{H}]$ complexes formed by reaction of $\mathrm{Ru}\left(\mathrm{PPh}_{3}\right)_{3} \mathrm{Cl}_{2}$ with ${ }^{n} \mathrm{BuLi}$. Interestingly, the formation of isomeric aldol products was not detected. ${ }^{49}$ They also explored the use of Ni hydride complexes in combination with $\mathrm{MgBr}_{2}$ as a co-catalyst. ${ }^{50}$ Aldols were obtained in good to excellent yields as single constitutional isomers. This is one of the most efficient catalytic systems for the formation of aldols from allylic alcohols reported to date. With the exception of a sterically hindered allylic alcohol, ${ }^{50 \mathrm{~b}}$ the catalysts developed by Grée and co-workers afforded low diastereoselectivity levels (i.e., mixture of $s y n$ and anti aldols). These catalytic systems have been successfully applied to the synthesis of tetraols, ${ }^{48 c} 1,3-$ diols $^{51 a}$ and indanones and indenones (Scheme 20). ${ }^{48 \mathrm{~d}, 51 \mathrm{~b}}$

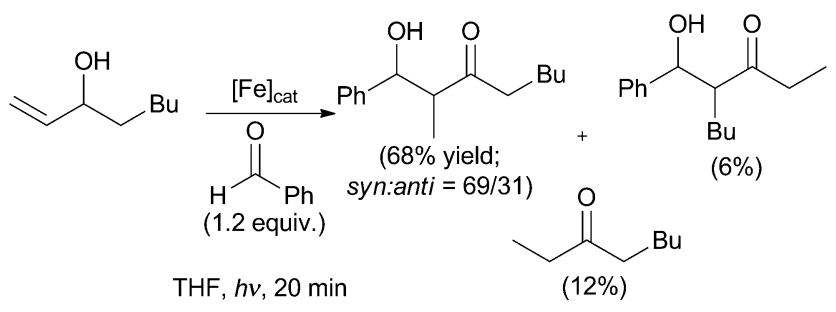

Scheme 19 Tandem isomerisation/aldol catalysed by $\mathrm{Fe}(\mathrm{CO})_{5}$. 


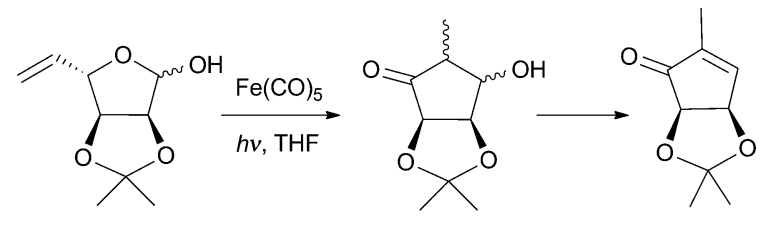

Scheme 20 Synthesis of indenones from a D-ribose derivative catalysed by $\mathrm{Fe}(\mathrm{CO})_{5}$.

$\mathrm{Li}$ and co-workers used $\mathrm{Ru}\left(\mathrm{PPh}_{3}\right)_{3} \mathrm{Cl}_{2}$ in toluene/ $\mathrm{H}_{2} \mathrm{O}$ mixtures in the coupling of allylic alcohols with a variety of aldehydes. ${ }^{52 a, b}$ Aldol products were obtained in moderate to good yields. In an extension of their work, they found that additives such as $\mathrm{In}(\mathrm{OAc})_{3}$ increased the yields of aldol products dramatically. ${ }^{52, \mathrm{~d}}$ The scope was also extended to include imines as electrophiles, synthesising for the first time Mannich-type products from allylic alcohols (Scheme 21). ${ }^{52, \mathrm{~d}}$ In contrast with the couplings described by Gree, these catalytic reactions use an excess of the allylic alcohol (2.5 equiv.).

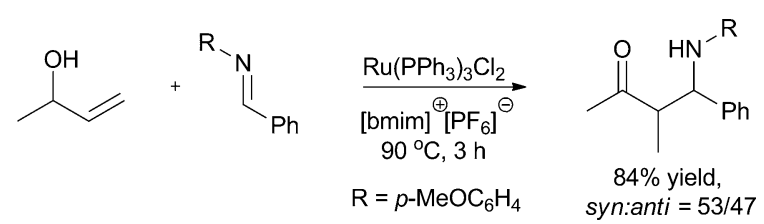

Scheme 21 Tandem isomerisation/Mannich-type reaction.

The group of Grée also reported Mannich couplings with $N$ phenylsulfonyl imines as electrophiles and $\mathrm{Fe}(\mathrm{CO})_{5}$ as catalyst. ${ }^{53}$ Recently, they used enantiopure $\mathrm{N}$-tert-butylsulfinimines as electrophiles in a diastereo and enantioselective synthesis of $\beta$-amino ketones and $\beta$-amino alcohols (Scheme 22). The method was used as the key step in the synthesis of ent-Nikkomycins and entFunebrine. ${ }^{54}$

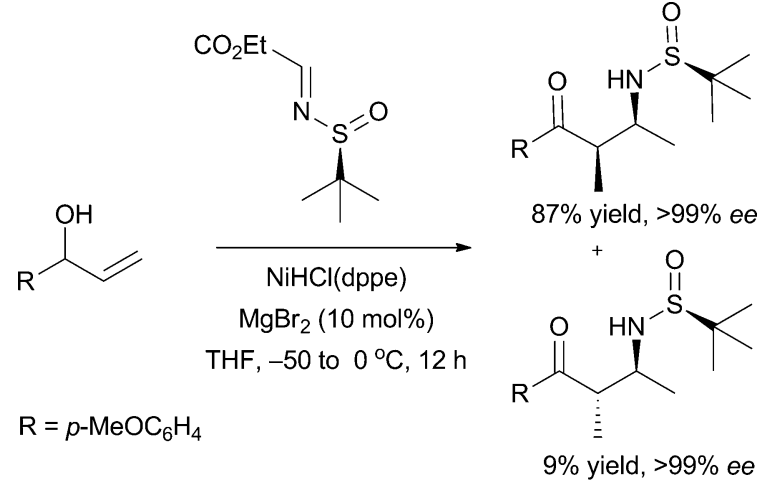

Scheme 22 Enantioselective tandem isomerisation/Mannich-type.

Our group reported that $\left[\eta^{5}-\left(\mathrm{Ph}_{5} \mathrm{C}_{5}\right) \mathrm{Ru}(\mathrm{CO})_{2} \mathrm{Cl}\right](\mathbf{1})$, which is used in racemisation of sec-alcohols ${ }^{55}$ and isomerisation of allylic alcohols ${ }^{6 c}$ is an excellent catalyst for tandem isomerisation/aldol reactions from allylic alcohols. ${ }^{35}$ During our mechanistic investigations, we found that ketone by-products can be formed not only via isomerisation of the allylic alcohols, but also via retro aldolisation of the final $\beta$-hydroxy ketones. ${ }^{35 b}$ This undesired retroaldolisation reaction was suppressed when the reaction was performed under mild reaction conditions (ambient temperature) and aldols could
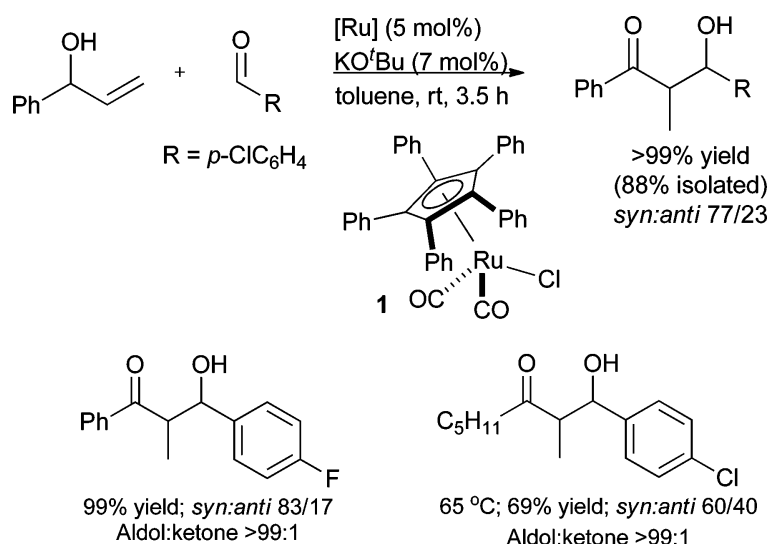

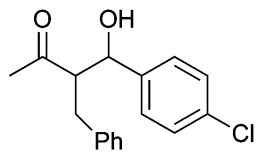

$50{ }^{\circ} \mathrm{C}$; $95 \%$ yield; syn:anti $40 / 60$ Aldol:ketone $>99: 1$

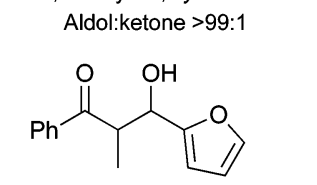

$99 \%$ yield; syn:anti $70 / 30$ Aldol:ketone $>99: 1$
Scheme 23 Synthesis of aldols from allylic alcohols catalysed by ruthenium complex $\mathbf{1}$.

be synthesised in up to $>99 \%$ yield (Scheme 23). By following the reactions by ${ }^{1} \mathrm{H}$ NMR spectroscopy, we also observed that the syn/anti diastereomeric ratio was remarkably high in favour of the syn aldol (syn: anti $=92: 8$ ) at the beginning of the reaction. However, this ratio changed as the reaction proceeded due to epimerisation of the final products catalysed by the ruthenium catalyst.

A series of investigations enabled us to elucidate a plausible mechanism for this reaction (Scheme 24). In the first step of the catalytic cycle, ruthenium chloride $\mathbf{1}$ reacts with $\mathrm{KO}^{\prime} \mathrm{Bu}$ forming a ruthenium tert-butoxide complex $\left(\mathrm{L}_{n} \mathrm{RuO}^{\prime} \mathrm{Bu}\right)$, as observed by NMR spectroscopy. ${ }^{55}$ Next, the substrate enters the cycle through an alkoxide exchange step. The following $\beta$-hydride elimination results in the formation of a ruthenium hydride species and an enone intermediate, which stays coordinated to the $\mathrm{Ru}$ centre. The next step is an intramolecular 1,4-hydride addition that yields

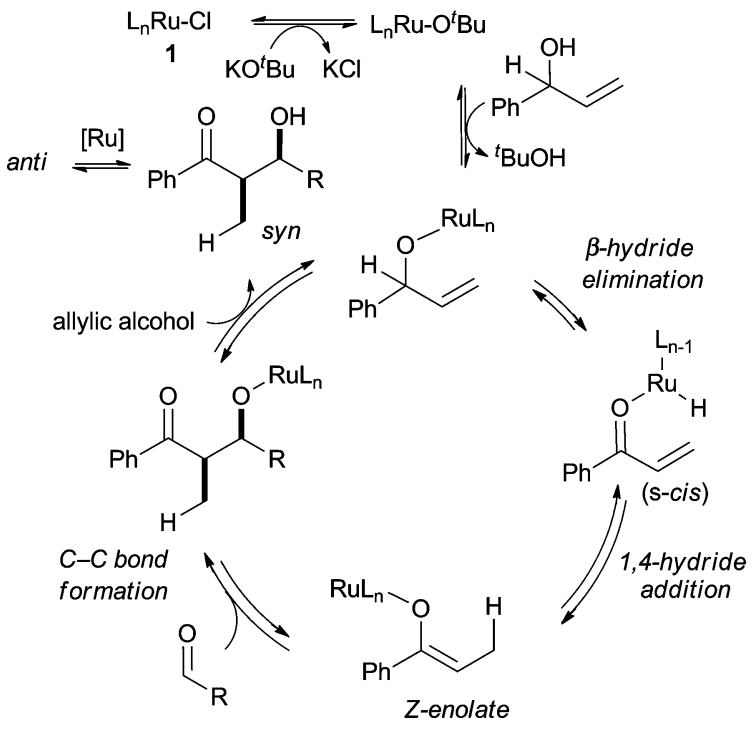

Scheme 24 Proposed mechanism for the tandem isomerisation/aldol reaction catalysed by ruthenium complex $\mathbf{1}$. 
a $Z(O)$-ruthenium enolate. We propose that for the 1,4-hydride addition to occur, the enone intermediate must adopt an s-cis conformation since certain cyclic allylic alcohols that are unable to adopt this conformation after oxidation failed to react (Scheme 25 ). In these last two consecutive steps, $\beta$-hydride elimination and 1,4-hydride addition, a 1,3-hydrogen shift occurs, which is supported by the outcome of the coupling shown in Scheme 26, where a deuterated allylic alcohol was used (Scheme 26). The $Z(O)$ enolate then reacts with the aldehyde through a ZimmermannTraxler six membered transition state, ${ }^{56}$ forming the syn aldol preferentially (syn: anti $=92: 8$ ). The anti-aldol is produced via $\mathrm{Ru}$ catalysed epimerisation of the $s y n$-aldol.

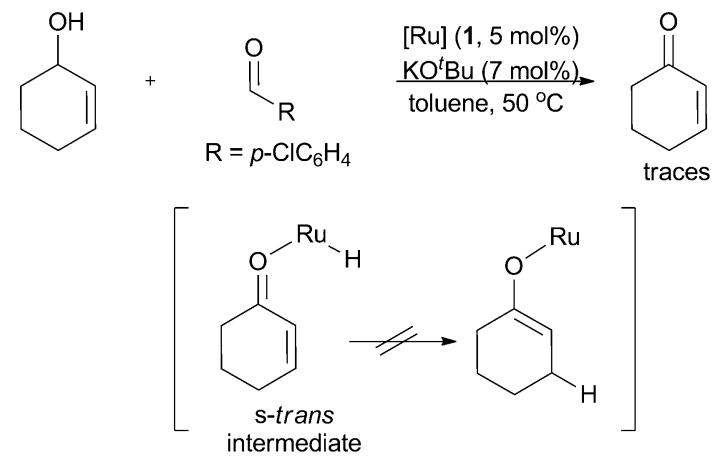

Scheme 25 Failed experiment with a cyclic allylic alcohol.

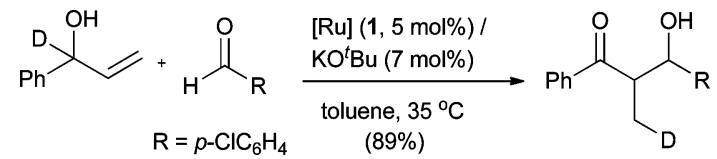

Scheme 26 Reaction of a deuterium-labelled allylic alcohol.

In our following work, we found that $[\mathrm{Rh}(\mathrm{COD}) \mathrm{Cl}]_{2}$ in combination with $\mathrm{PPh}_{3}$ and ${ }^{t} \mathrm{BuOK}$ in wet THF catalysed the tandem isomerisation/aldol and Mannich-type reactions when using aldehydes or $N$-tosyl imines as electrophiles, respectively (Scheme 27). The diastereoselectivities obtained (syn/anti ratio) ranged from moderate to low, and in some cases traces of isomeric aldols were detected. Interestingly, the substrate could be an allylic, homoallylic or bishomoallylic alcohol. ${ }^{57}$ As for catalyst 1, we confirmed by NMR spectroscopy that the role of ${ }^{t} \mathrm{BuOK}$ is to promote chloride substitution from the pre-catalyst. Thus, rhodium alkoxides are also key intermediates in the catalytic cycle. Furthermore, we confirmed by ${ }^{1} \mathrm{H}$ NMR spectroscopy that a rhodium allylic alkoxide is formed: the two vinylic COD protons cis to the alkoxide chiral ligand (Fig. 4) showed a diastereotopic splitting, consistent with the coordination of the chiral allylic alcohol to the Rh centre. Although it was detected as a ligand in the

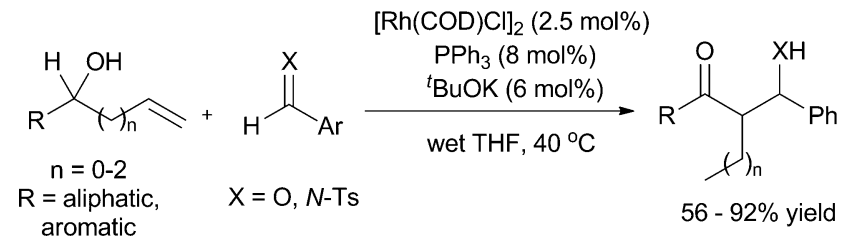

Scheme 27 Rhodium-catalysed coupling of allylic, homoallylic and bishomoallylic alcohols with aldehydes and $N$-tosyl imines.

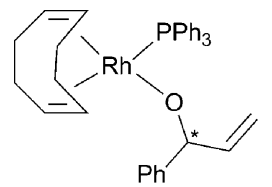

Fig. 4 Rhodium allylic alkoxide complex.

NMR studies, the cyclooctadiene may or may not stay coordinated to the Rh during the reaction. As we had observed when using $\mathrm{Ru}$ complex 1 (Scheme 26, vide supra), in the isomerisation of an $\alpha$-deuterated allylic alcohol/aldol reaction catalysed by this rhodium system, there is a 1,3-hydrogen (deuterium) migration. In contrast with the ruthenium (1) system, the rhodium-catalysed reaction affords the product with low diastereoselectivity already at low conversions. Such a lack of selectivity may be explained by: (i) formation of a mixture of $Z(O)$ - and $E(O)$-enolates, (ii) rapid interconversion between $Z(O)$ - and $E(O)$-enolates (via formation of $C$-bound enolates and rotation around the $\mathrm{C}(\alpha)-\mathrm{C}=\mathrm{O}$ single bond), ${ }^{58}$ (iii) non Zimmermann-Traxler transition state in the $\mathrm{C}_{-}$ $\mathrm{C}$ bond forming step, or (iv) fast Rh catalysed epimerisation of the aldol products.

The use of allylic alcohols as enolate precursors in total syntheses is still in its infancy. However, in the last couple of years, excellent applications of this methodology have been reported. For example, and in addition to the interesting examples reported by Grée (vide supra) ${ }^{48,51}$ Iwasawa and co-workers recently reported an impressive synthesis of $\gamma$-pyrones by three consecutive redox aldol reactions of allylic alcohols with $\alpha, \beta$-unsaturated aldehydes (Scheme 28). ${ }^{59}$

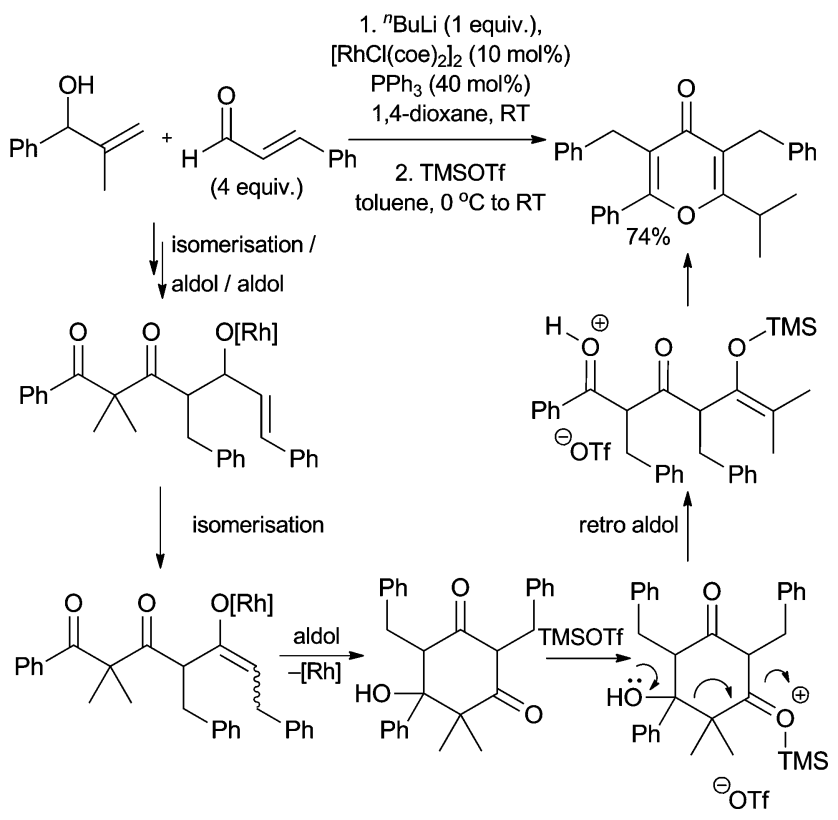

Scheme 28 Synthesis of $\gamma$-pyrones from allylic alcohols.

In the examples presented above, reaction intermediates formed during the isomerisation of allylic alcohols are trapped by electrophiles (aldehydes or imines) resulting in the formation of a new $\mathrm{C}-\mathrm{C}$ bond at the $\alpha$ position of the carbonyl moiety. The next few examples show a different approach that also increases molecular complexity but does not involve electrophilic trapping of reaction intermediates. In these examples, the ketones produced 
upon isomerisation of allylic alcohols are further functionalised in a consecutive step by the same transition metal complex. For example, Cadierno et al. combined a Ru catalysed isomerisation of allylic alcohols with a transfer hydrogenation using ${ }^{i} \mathrm{PrOH}$ as hydrogen donor (Scheme 29) ${ }^{60}$ Bruneau and co-workers recently merged an allylic alcohol isomerisation with in situ formation of an imine (or imminium cation) intermediate, which is further reduced by the same ruthenium complex using formic acid as hydrogen donor (Scheme 30). ${ }^{61}$ Our group has combined the isomerisation with a Murai-type ${ }^{62} \mathrm{C}-\mathrm{H}$ activation process using ruthenium catalysis (Scheme 31) ${ }^{63}$ The in situ generated carbonyl functional group assists the cleavage of the ortho aromatic $\mathrm{C}-\mathrm{H}$ bond by chelation. Both processes are catalysed by the same ruthenium source.

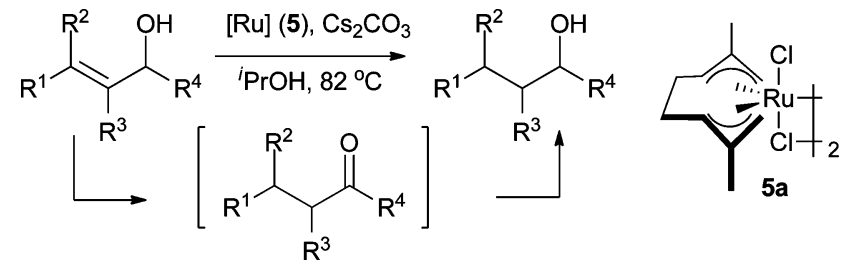

Scheme 29 Consecutive isomerisation and reduction catalysed by ruthenium complex $\mathbf{5}$.

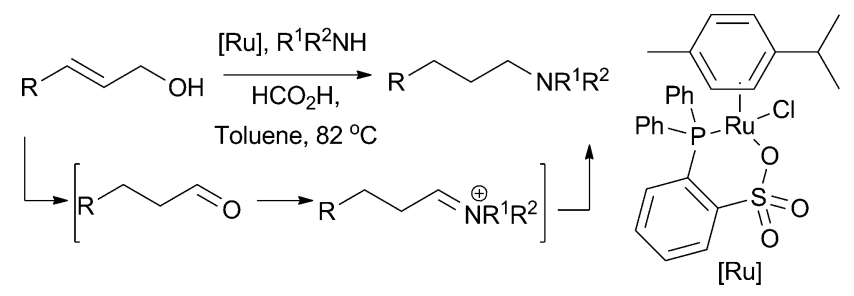

Scheme 30 Isomerisation, imine (iminium cation) formation and reduction catalysed by a ruthenium complex.

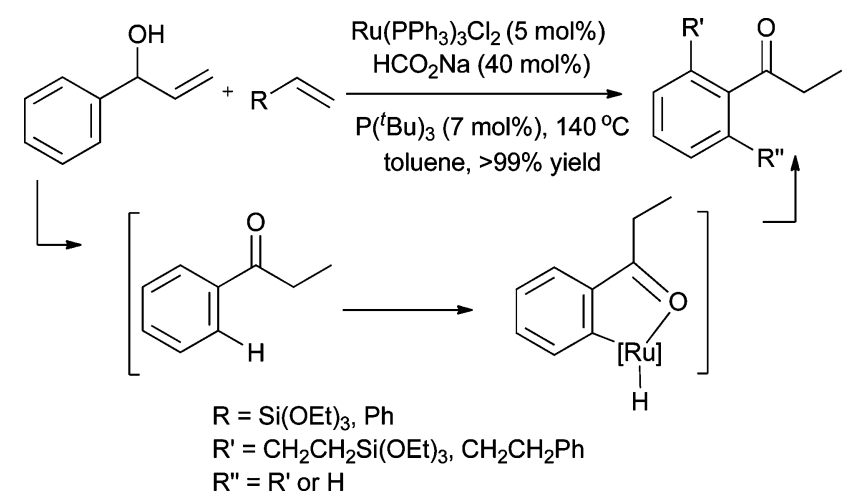

Scheme 31 Consecutive isomerisation and $\mathrm{C}-\mathrm{H}$ bond activation catalysed by $\mathrm{Ru}\left(\mathrm{PPh}_{3}\right)_{3} \mathrm{Cl}_{2}$.

\subsection{Tandem isomerisation/C-F bond formation}

Synthesis of $\alpha$-fluroketones from carbonyl compounds can be achieved using a variety of electrophilic fluorinating reagents (Fig. 5), in a process that can be mediated by organometallic Lewis acids or organocatalysts. ${ }^{64,65,66}$ However, methods for the<smiles>O=[Pb]1CCC2CCC(C1)N2CCCl</smiles>

Selectfluor ${ }^{\circledR}$<smiles>O=S(=O)(c1ccccc1)N(F)S(=O)(=O)c1ccccc1</smiles>

$N$-Fluorobenzene-sulfonamide (NFSI)<smiles>F[n+]1ccccc1</smiles>

$\mathrm{N}$-Fluoropyridinium tetrafluoroborate
Fig. 5 Electrophilic fluorinating reagents.

specific synthesis of fluorinated ketones from unsymmetrical or non-activated ketones are still rare. With the aim of obtaining high regiocontrol in the synthesis of $\alpha$-fluoroketones, we have combined the transition-metal-catalysed isomerisation of allylic alcohols with an electrophilic fluorination (Scheme 32 ) ${ }^{67,68}$ This is the first example of a tandem allylic alcohol isomerisation/carbonheteroatom bond formation. To achieve this challenging transformation, a transition metal catalytic system and reaction conditions compatible with highly reactive fluorinating reagents had to be found. ${ }^{69}$

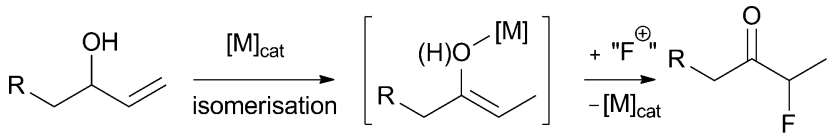

Scheme 32 Transition-metal-catalysed isomerisation/fluorination of allylic alcohols.

The use $\left[\mathrm{IrCp}^{*} \mathrm{Cl}_{2}\right]_{2}$ and Selectfluor in THF/water mixtures resulted in a very efficient system for the tandem isomerisation/fluorination under very mild (ambient temperature to $30^{\circ} \mathrm{C}$ ) and non-inert conditions. Catalyst loadings of $2 \mathrm{~mol} \%$ could be used to synthesise a variety of aliphatic and aromatic fluoroketones as single constitutional isomers (Scheme 33). The fluorine atom could also be introduced onto a tetrasubstituted carbon, and additional functional groups including alcohols were well tolerated. Importantly, the reaction displays complete chemoselectivity for allylic alcohols, which enables substrates with additional carbonyl moieties to selectively undergo fluorination exclusively at the allylic alcohol functionality. We took advantage of this chemoselectivity to synthesise fluorinated 1,3-dicarbonyl compounds with the

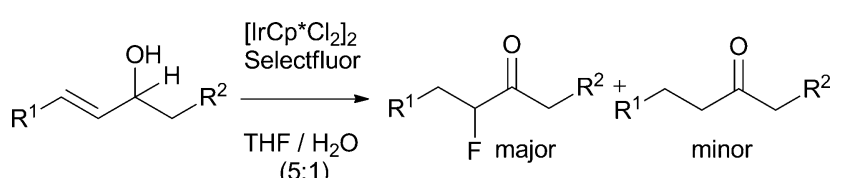
$(5: 1)$<smiles>CC(F)C(=O)CCc1ccccc1</smiles><smiles>CC(=O)C(F)Cc1ccccc1</smiles><smiles>[18OH][131In]</smiles>
$78 \%(67 \%)$

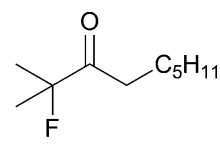<smiles>CC(F)C(=O)CC(O)C1CCCCC1</smiles><smiles>CCOC(=O)CC(=O)C(C)F</smiles>
$60 \%$ $61 \%$

$80 \%(63 \%)$

$$
\begin{aligned}
& \mathrm{R}=m-\mathrm{PhOC}_{6} \mathrm{H}_{4} 91 \%(75 \%) \\
& \mathrm{R}=p-\mathrm{CF}_{3} \mathrm{C}_{6} \mathrm{H}_{4} 81 \%(69 \%)
\end{aligned}
$$

Scheme 33 Tandem isomerisation/fluorination mediated by iridium and Selectfluor (yields are calculated using an internal standard, isolated yields are given in parentheses). 
fluorine atom at the less acidic $\alpha$-carbon (Scheme 33). By running the control experiment shown in Scheme 34, it was confirmed that non-fluorinated ketones are not intermediates in the catalytic cycle. As observed in our previous studies when using aldehydes as electrophiles, ${ }^{35,57}$ the isomerisation/fluorination of an $\alpha$-deuterated allylic alcohol showed that a 1,3-hydrogen (deuterium) shift occurs (Scheme 35). The hydride is transferred intramolecularly, as concluded from the crossover experiment shown in Scheme 36, where the fluorination of a deuterated allylic alcohol in the presence of a structurally similar non-deuterated allylic alcohol was carried out in one pot (Scheme 36).<smiles>C=CC(O)CCc1ccccc1</smiles>

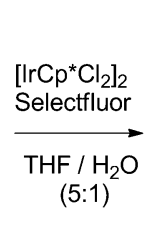

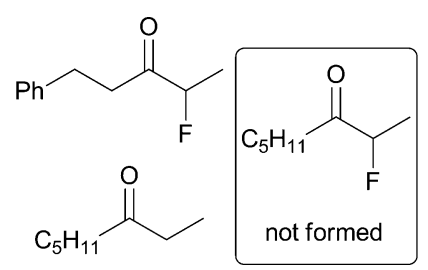

Scheme 34 Crossover experiment.

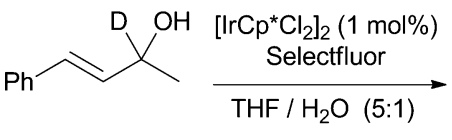

(96\% D)

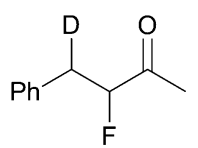

(95\% D)
Scheme 35 Fluorination of a deuterium-labelled allylic alcohol.<smiles>CC(O)/C=C/[13CH][13CH]c1ccccc1</smiles>

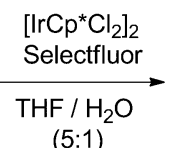

$(5: 1)$

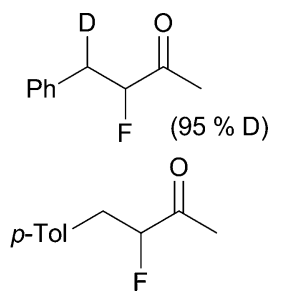

Scheme 36 The 1,3-hydrogen shift is an intramolecular process.

\section{Conclusions}

Allylic alcohols are versatile precursors of both unfunctionalised and $\alpha$-functionalised carbonyl compounds. In the past decade, numerous efforts have contributed to the development of new transition metal catalysts for redox isomerisation of primary and secondary allylic alcohols, and also for its combination with $\mathrm{C}-\mathrm{C}$ or $\mathrm{C}-\mathrm{F}$ bond formation. Several highly efficient systems that are active under very mild reaction conditions, in organic, biphasic or aqueous media have been reported. In addition, highly enantioselective catalysts for the long-time difficult goal of asymmetric isomerisation have been developed, allowing the preparation of chiral aldehydes from primary allylic alcohols. Undoubtedly, the next coming years will witness the development of more efficient catalytic systems able to broaden the scope of the transition-metal-catalysed tandem transformations of allylic alcohols.

\section{Acknowledgements}

Financial support from the Swedish Research Council (VR), the Swedish Governmental Agency for Innovation Systems (VINNOVA), the Knut and Alice Wallenberg Foundation, and the Berzelii Center EXSELENT is gratefully acknowledged.

\section{Notes and References}

1 R. C. van der Drift, E. Bouwman and E. Drent, J. Organomet. Chem., 2002, 650, 1-24.

2 R. Uma, C. Crévisy and R. R. Grée, Chem. Rev., 2003, 103, 27-51.

3 V. Cadierno, P. Crochet and J. Gimeno, Synlett, 2008, 11051124.

4 For a highlight review, see: L. Mantilli and C. Mazet, Chem. Lett., 2011, 40, 341-344.

5 B. M. Trost, Science, 1991, 254, 1471-1477.

6 For highly efficient recent examples using organic solvents, see: (a) R. Uma, M. K. Davies, C. Crévisy and R. Grée, Eur. J. Org. Chem., 2001, 10, 3141-3146; (b) H. Cherkaoui, M. Soufiaoui and R. Grée, Tetrahedron, 2001, 57, 2379-2383; (c) B. Martín-Matute, K. Bogár, M. Edin, F. B. Kaynak and J.-E. Bäckvall, Chem.-Eur. J., 2005, 11, 5832 5842; (d) M. Ito, S. Kitahara and T. Ikariya, J. Am. Chem. Soc., 2005, 127, 6172-6173; (e) M. T. Reetz and H. Guo, Synlett, 2006, 2127 2129; $(f)$ A. Bouziane, B. Carboni, C. Bruneau, F. Carreaux and J.-L. Renaud, Tetrahedron, 2008, 64, 11745-11750; $(g)$ L. Mantilli and C. Mazet, Tetrahedron Lett., 2009, 50, 4141-4144; $(h)$ P. N. Liu, K. D. Ju and C. P. Lau, Adv. Synth. Catal., 2011, 353, 275-280.

7 (a) L. Mantilli, D. Gérard, S. Torche, C. Besnard and C. Mazet, Angew. Chem., Int. Ed., 2009, 48, 5143-5147; (b) L. Mantilli and C. Mazet, Chem. Commun., 2010, 46, 445-447; (c) L. Mantilli, D. Gérard, S. Torche, C. Besnard and C. Mazet, Chem.-Eur. J., 2010, 16, 12736 12745; (d) A. Quintard, A. Alexakis and C. Mazet, Angew. Chem. Int. Ed., 2011, 50, 2354-2358.

8 P. Crochet, M. A. Fernández-Zúmel, J. Gimeno and M. Scheele, Organometallics, 2006, 25, 4846-4849.

9 R. Damico and T. Logan, J. Org. Chem., 1967, 32, 2356-2358.

10 M. Batuecas, M. A. Esteruelas, C. García-Yebra and E. Oñate, Organometallics, 2010, 29, 2166-2175.

11 (a) T. Tatsumi, K. Hashimoto, H. Tominaga, Y. Mizuta, K. Hata, M. Hidai and Y. Uchida, J. Organomet. Chem., 1983, 252, 105-112; (b) W. Strohmeier and L. Weigelt, J. Organomet. Chem., 1975, 86, C17-C19; (c) B. M. Trost and R. J. Kulawiec, Tetrahedron Lett., 1991, 32, 30393042; (d) B. M. Trost and R. J. Kulawiec, J. Am. Chem. Soc., 1993, 115, 2027-2036; (e) C. Bianchini, A. Meli and W. Oberhauser, New J. Chem., 2001, 25, 11-12; (f) C. M. Beck, S. E. Rathmill, Y. J. Park, J. Chen, R. H. Crabtree, L. M. Liable-Sands and A. L. Rheingold, Organometallics, 1999, 18, 5311-5317.

12 For a water-soluble Ru complex able to isomerise allyl alcohol, see: J. García-Álvarez, J. Gimeno and F. J. Suárez, Organometallics, 2011, 30, 2893-2896.

13 (a) M. Kitamura, K. Manabe, R. Noyori and H. Takaya, Tetrahedron Lett., 1987, 28, 4719-4720; (b) J. A. Wiles, C. E. Lee, R. McDonald and S. H. Bergens, Organometallics, 1996, 15, 3782-3784.

14 K. Tani, Pure Appl. Chem., 1985, 57, 1845-1854.

15 K. Tanaka, S. Qiao, M. Tobisu, M. M. C. Lo and G. C. Fu, J. Am. Chem. Soc., 2000, 122, 9870-9871.

16 J.-Q. Li, B. Peters and P. G. Andersson, Chem.-Eur. J., 2011, 17, $11143-$ 11145.

17 N. Pinault and D. W. Bruce, Coord. Chem. Rev., 2003, 241, 1-25.

18 (a) V. Cadierno, S. E. García-Garrido, J. Gimeno, A. Varela-Álvarez and J. A. Sordo, J. Am. Chem. Soc., 2006, 128, 1360-1370.

19 D. V. McGrath and R. H. Grubbs, Organometallics, 1994, 13, 224 235.

20 (a) A. E. Díaz-Álvarez, P. Crochet, M. Zablocka, C. Duhayon, V. Cadierno, J. Gimeno and J. P. Majoral, Adv. Synth. Catal., 2006, 348, 1671-1679; (b) B. Lastra-Barreira, J. Díez and P. Crochet, Green Chem., 2009, 11, 1681-1686; (c) V. Cadierno, S. E. García-Garrido and J. Gimeno, Chem. Commun., 2004, 232-233; (d) J. Díez, J. Gimeno, I. Merino, E. Rubio and F. J. Suárez, Inorg. Chem., 2011, 50, 4868 4881; (e) V. Cadierno, P. Crochet, S. E. García-Garrido and J. Gimeno, Dalton Trans., 2004, 3635-3641; (f) J. García-Álvarez, J. Gimeno and F. J. Suárez, Organometallics, 2011, 30, 2893-2896. 
21 (a) M. Fekete and F. Joó, Catal. Commun., 2006, 7, 783-786; (b) B. González, P. Lorenzo-Luis, M. Serrano-Ruiz, É. Papp, M. Fekete, K. Csépke, K. Osz, Á. Kathó, F. Joó and A. Romerosa, J. Mol. Catal. A: Chem., 2010, 326, 15-20; (c) T. Campos-Malpartida, M. Fekete, F. Joó, Á. Kathó, A. Romerosa, M. Saoud and W. Wojtków, J. Organomet. Chem., 2008, 693, 468-474.

22 For $\mathrm{Rh}$ and $\mathrm{Ru}$ complexes incorporated into a water-soluble supramolecular assembly, see: (a) C. J. Brown, G. M. Miller, M. W. Johnson, R. G. Bergman and K. N. Raymond, J. Am. Chem. Soc., 2011, 133, 11964-11966; (b) D. H. Leung, R. G. Bergman and K. N. Raymond, J. Am. Chem. Soc., 2007, 129, 2746-2747.

23 (a) A. P. da Costa, J. A. Mata, B. Royo and E. Peris, Organometallics, 2010, 29, 1832-1838; (b) A. Azua, S. Sanz and E. Peris, Organometallics, 2010, 29, 3661-3664

24 P. Servin, R. Laurent, L. Gonsalvi, M. Tristany, M. Peruzzini, J.-P. Majoral and A.-M. Caminade, Dalton Trans., 2009, 4432-4434.

25 C. de Bellefon, S. Caravieilhes and É. G. Kuntz, C. R. Acad. Sci., Ser. IIc: Chim., 2000, 3, 607-614.

26 D. A. Knight and T. L. Schull, Synth. Commun., 2003, 33, 827-831.

27 Y. Sasson, A. Zoran and J. Blum, J. Mol. Catal., 1981, 11, 293-300.

28 H. Alper and K. Hachem, J. Org. Chem., 1980, 45, 2269-2270.

29 H. Bricout, E. Monflier, J.-F. Carpentier and A. Mortreux, Eur. J. Inorg. Chem., 1998, 1739-1744.

30 N. Ahlsten, H. Lundberg and B. Martín-Matute, Green Chem., 2010, 12, 1628-1633.

31 (a) K. Yamaguchi, T. Koike, M. Kotani, M. Matsushita, S. Shinachi and N. Mizuno, Chem.-Eur. J., 2005, 11, 6574-6582; (b) J. W. Kim, T. Koike, M. Kotani, K. Yamaguchi and N. Mizuno, Chem.-Eur. J., 2008, 14, 4104-4109.

32 S. Sahoo, H. Lundberg, M. Edén, N. Ahlsten, W. Wan, X. Zou and B. Martín-Matute, Chem. Cat. Chem., 2011, 10.1002/cctc.201100321.

33 During the editing of this manuscript, a new computational study has been published: A. Varela-Álvarez, J. A. Sordo, E. Piedra, N. Nebra, V. Cadierno and J. Gimeno, Chem.-Eur. J., 2011, 17, 10583-10599.

34 (a) G. A. Slough, R. G. Bergman and C. H. Heathcock, J. Am. Chem. Soc., 1989, 111, 938-949; (b) J. F. Hartwig, R. G. Bergman and R. A. Andersen, Organometallics, 1991, 10, 3326-3344.

35 (a) A. Bartoszewicz, M. Livendahl and B. Martín-Matute, Chem.-Eur. J., 2008, 14, 10547-10550; (b) A. Bartoszewicz, M. M. Jeżowska, K. Laymand, J. Möbus and B. Martín-Matute, Eur. J. Inorg. Chem., 2011, DOI: $10.1002 /$ ejic. 201101014.

36 R. L. Chowdhury and J.-E. Bäckvall, J. Chem. Soc., Chem. Commun., 1991, 1063-1064.

37 J.-E. Bäckvall and U. Andreasson, Tetrahedron Lett., 1993, 34, 54595462.

38 F. G. Cowherd and J. L. Von Rosenberg, J. Am. Chem. Soc., 1969, 91, $2157-2158$

39 V. Branchadell, C. Crévisy and R. Grée, Chem.-Eur. J., 2004, 10, $5795-$ 5803.

40 T. D. Sheppard, Synlett, 2011, 1340-1344.

41 (a) G. Stork, P. Rosen and N. L. Goldman, J. Am. Chem. Soc., 1961, 83, 2965-2966; (b) G. Stork, P. Rosen, N. Goldman, R. V. Coombs and J. Tsuji, J. Am. Chem. Soc., 1965, 87, 275-286.

42 R. R. Huddleston and M. J. Krische, Synlett, 2003, 12-21.

43 S. B. Han, A. Hassan and M. J. Krische, Synthesis, 2008, 2669-2679.

44 (a) S. Garner, S. B. Han and M. J. Krische, In Modern Reduction MethodsP. Andersson, I. Munslow, ed.; Wiley-VCH: Weinheim, 2008; p 387-408; (b) H. Nishiyama and T. Shiomi, Top. Curr. Chem., 2007, 279, 105-137.

45 L. F. Tietze, Chem. Rev., 1996, 96, 115-136.

46 S. H. Bergens and B. Bosnich, J. Am. Chem. Soc., 1991, 113, 958-967.

47 J. L. Gazzard, B. W. Motherwell and A. D. Sandham, J. Chem. Soc., Perkin Trans. 1, 1999, 979-994.

48 (a) C. Crévisy, M. Wietrich, V. Le Boulaire, R. Uma and R. Grée, Tetrahedron Lett., 2001, 42, 395-398; (b) R. Uma, N. Gouault, C.
Crévisy and R. Grée, Tetrahedron Lett., 2003, 44, 6187-6190; (c) D. Cuperly, C. Crévisy and R. Grée, J. Org. Chem., 2003, 68, 6392-6399; (d) J. Petrignet, T. Roisnel and R. Grée, Chem.-Eur. J., 2007, 13, 7374 7384.

49 R. Uma, M. Davies, C. Crévisy and R. Grée, Tetrahedron Lett., 2001, 42, 3069-3072.

50 (a) D. Cuperly, C. Crévisy and R. Grée, Synlett, 2004, 93-96; (b) D. Cuperly, J. Petrignet, C. Crévisy and R. Grée, Chem.-Eur. J., 2006, 12, 3261-3274.

51 (a) J. Petrignet, T. Roisnel and R. Grée, Tetrahedron Lett., 2006, 47, 7745-7748; (b) J. Petrignet, I. Prathap, S. Chandrasekhar, J. S. Yadav and R. Grée, Angew. Chem., Int. Ed., 2007, 46, 6297-6300.

52 (a) M. Wang and C.-J. Li, Tetrahedron Lett., 2002, 43, 3589-3591; (b) M. Wang, X.-F. Yang and C.-J. Li, Eur. J. Org. Chem., 2003, 9981003; (c) X.-F. Yang, M. Wang, R. S. Varma and C.-J. Li, Org. Lett., 2003, 5, 657-660; (d) X.-F. Yang, M. Wang, R. S. Varma and C.-J. Li, J. Mol. Catal. A: Chem., 2004, 214, 147-154.

53 H. T. Cao, T. Roisnel and R. Grée, Lett. Org. Chem., 2009, 6, 507-510.

54 H. T. Cao, T. Roisnel, A. Valleix and R. Grée, Eur. J. Org. Chem., 2011, 3430-3436.

55 (a) B. Martín-Matute, M. Edin, K. Bogár and J.-E. Bäckvall, Angew. Chem., Int. Ed., 2004, 43, 6535-6539; (b) B. Martín-Matute, M. Edin, K. Bogár, F. B. Kaynak and J.-E. Bäckvall, J. Am. Chem. Soc., 2005, 127, 8817-8825.

56 H. E. Zimmerman and M. D. Traxler, J. Am. Chem. Soc., 1957, 79, 1920-1923.

57 N. Ahlsten and B. Martín-Matute, Adv. Synth. Catal., 2009, 351, 26572666.

58 C.-K. Jung, S. A. Garner and M. J. Krische, Org. Lett., 2006, 8, 519522 .

59 A. Mizuno, H. Kusama and N. Iwasawa, Chem.-Eur. J., 2010, 16, $8248-8250$.

60 (a) V. Cadierno, J. Francos, J. Gimeno and N. Nebra, Chem. Commun., 2007, 2536-2538; (b) V. Cadierno, P. Crochet, J. Francos, S. E. GarcíaGarrido, J. Gimeno and N. Nebra, Green Chem., 2009, 11, 1992-2000.

61 Z. Sahli, B. Sundararaju, M. Achard and C. Bruneau, Org. Lett., 2011, 13, 3964-3967.

62 S. Murai, F. Kakiuchi, S. Sekine, Y. Tanaka, A. Kamatani, M. Sonoda and N. Chatani, Nature, 1993, 366, 529-531.

63 A. Bartoszewicz and B. Martín-Matute, Org. Lett., 2009, 11, 1749 1752.

64 (a) P. T. Nyffeler, S. G. Duron, M. D. Burkart, S. P. Vincent and C.-H. Wong, Angew. Chem., Int. Ed., 2005, 44, 192-212; (b) D. Cahard, X. Xu, S. Couve-Bonnaire and X. Pannecoucke, Chem. Soc. Rev., 2010, 39, 558-568; (c) S. Lectard, Y. Hamashima and M. Sodeoka, Adv. Synth. Catal., 2010, 352, 2708-2732; (d) Y. K. Kang and D. Y. Kim, Curr. Org. Chem., 2010, 14, 917-927; (e) V. A. Brunet and D. O'Hagan, Angew. Chem., Int. Ed., 2008, 47, 1179-1182; (f) P. M. Pihko, Angew. Chem., Int. Ed., 2006, 45, 544-547; (g) H. Ibrahim and A. Togni, Chem. Commun., 2004, 1147-1155; (h) P. Kwiatkowski, T. D. Beeson, J. C. Conrad and D. W. C. MacMillan, J. Am. Chem. Soc., 2011, 133, 1738-1741.

65 (a) S. D. Taylor, C. C. Kotoris and G. Hum, Tetrahedron, 1999, 55, 12431-12477; (b) F. A. Davis and P. V. N. Kasu, Org. Prep. Proced. Int., 1999, 31, 125-143; (c) J. A. Wilkinson, Chem. Rev., 1992, 92, 505-519.

66 (a) G. Stavber and S. Stavber, Adv. Synth. Catal., 2010, 352, 2838-2846; (b) G. Stavber, M. Zupan and S. Stavber, Synlett, 2009, 589-594; (c) S. Stavber, M. Jereb and M. Zupan, Chem. Commun., 2000, 1323-1324.

67 N. Ahlsten and B. Martín-Matute, Chem. Commun., 2011, 47, 83318333.

68 N. Ahlsten, A. Bartoszewicz, S. Agrawal and B. Martín-Matute, Synthesis, 2011, 2600-2608.

69 For Pd catalysed fluorination reactions, see: (a) J. M. Brown and V. Gouverneur, Angew. Chem., Int. Ed., 2009, 48, 8610-8614; (b) T. Furuya, J. E. M. N. Klein and T. Ritter, Synthesis, 2010, 1804-1821; (c) T. W. Lyons and M. S. Sanford, Chem. Rev., 2010, 110, 1147-1169. 